\title{
Dissimilar friction stir lap welding of AA2198 and AA7075 sheets: forces, microstructure and mechanical properties
}

\author{
Antonello Astarita $^{1}$ - Fausto Tucci $^{2}$ - Alessia Teresa Silvestri ${ }^{1} \cdot$ Michele Perrella $^{1} \cdot$ Luca Boccarusso $^{1}$. \\ Pierpaolo Carlone ${ }^{2}$
}

Received: 17 February 2021 / Accepted: 26 July 2021 / Published online: 4 August 2021

(C) The Author(s) 2021

\begin{abstract}
This paper investigates the dissimilar friction stir lap welding of AA2198 and AA7075 sheets. The influence of processing parameters, namely welding speed and tool rotational speed on joint features, microstructure, and mechanical properties were studied by implementing a full factorial design of experiments. Axial and transversal forces were continuously measured during the welding process using a sensed fixture aiming at the correlation of processing parameters, forces, and quality of the achieved joints. Obtained outcomes showed hook formation for all the combination of parameters and the existence of a very narrow processing window in which it is possible to avoid the formation of internal defects, such as grooves and tunnels. The influence of the weld bead morphology on the lap shear strength was elucidated proving that the strength is ruled by the hook morphology. The microstructure of the joints was studied and discussed considering also the microhardness distribution.
\end{abstract}

Keywords FSW $\cdot$ Dissimilar joint $\cdot$ Lap joint $\cdot$ Aluminum alloys $\cdot$ Microstructure $\cdot$ Force analysis $\cdot$ Mechanical properties

\section{Introduction}

Aluminum alloys belonging to $2 \mathrm{xxx}$ (Al-Li) and 7xxx (Al-Zn) series are increasingly used in the aerospace industry to realize multi-material welded or assembled structures. An example of the advantageous combination of these materials in welded structures is represented by fuselage panels of aircraft, that are usually made of AA 2024 skins and strengthened by lap joining of AA 7075 stringers [1]. Due to low density, high specific modulus, and specific strength, Al-Li alloys are considered optimal candidates for aerospace and aircraft vehicles [2]. Yin et al. [3] reported that alloys belonging to the recently developed third generation of damage-tolerant Al-Li alloys, such as AA2198, exhibit relatively higher mechanical properties. Zhang et al. claimed that superior properties are attributable mostly to the precipitation of the $\mathrm{T}_{1}\left(\mathrm{Al}_{2} \mathrm{CuLi}\right)$ phase [4],

Antonello Astarita

antonello.astarita@unina.it

1 Department of Chemical, Materials and Production Engineering, University of Naples “Federico II", P.le Tecchio 80,

80125 Naples, Italy

2 Department of Industrial Engineering, University of Salerno, Via Giovanni Paolo II, 132 Fisciano, Italy whereas Milagre et al. [5] proved that the attendance of $\mathrm{Li}$ lower density and enhance stiffness. In contrast, Xu et al. [6] and lately Krug et al. [7] argued that the previous generations of Al-Li alloys, e.g., 2020 alloy $(\mathrm{Al}-1.21 \mathrm{Li}-4.45 \mathrm{Cu}-$ $0.51 \mathrm{Mn}-0.20 \mathrm{Cd}$, in wt\%) and 8090 alloy (Al-2.5Li$1.11 \mathrm{Cu}-1.16 \mathrm{Mg}-0.16 \mathrm{Zr}$, in wt $\%$ ) exhibited limited ductility and significant anisotropy in mechanical properties.

Friction stir welding (FSW) process is currently considered to be sufficiently mature to be applied for aircraft manufacturing and its suitability to join dissimilar aluminum alloys in distinct configurations has been already demonstrated [8]. Among other welding processes, FSW leads to the reduction of metallurgical defects and distortion [9] as well as to weight and cost savings of up to $15 \%$ and $20 \%$, respectively [10]. On the other hand, some authors highlighted that the mechanical behavior of welded structures is affected by the quality of the joints, that, in turn, is dictated by the adopted processing parameters [11, 12].

In the past decades, a relevant amount of work has been spent to investigate FSW process for similar and dissimilar welding of Al- $\mathrm{Li}$ and $\mathrm{Al}-\mathrm{Zi}-\mathrm{Mg}$ alloys $[13,14]$. Recent papers proved the feasibility of similar FSW of AA2198, even if they were limited to the butt joint configuration. It is generally claimed that FSW of this material is characterized by a narrow processing window and that working parameters significantly 
influence microstructural aspects and, as a consequence, fatigue life and tensile strength [15, 16]. Gao et al. [17] studied the strengthening mechanism, the microstructure, and the precipitation evolution in the different metallurgical zones of butt joint, providing a comprehensive overview of the phenomena occurring across the joint. Tao et al. [18] elucidated the crack propagation and the failure modes of AA 2198 friction stir welded butt joints; they claimed that the transition zone between the stirred zone and the thermomechanical affected zone is the weakest part of the joint. It has been also outlined that the strength of the joint is influenced by the relationship between rolling and welding direction $[19,20]$.

To date, literature reporting the friction stir lap welding of AA 2198 sheets is scarce, despite of the interesting opportunities related to applications in the aerospace sector. One of the earliest study on this topic was authored by Gibson et al. [21]. The joints produced at welding speeds of 200 and 350 $\mathrm{mm} / \mathrm{min}$ exhibited higher ultimate load in tension-shear testing, compared to joints welded at $75 \mathrm{~mm} / \mathrm{min}$. Moreover, the blanks welded using tool rotational speeds of $1200 \mathrm{rpm}$ and $1500 \mathrm{rpm}$ resulted remarkably more resistant than the ones welded at $900 \mathrm{rpm}$. More recently, Reimann et al. [22] attempted AA2198 FSW process monitoring by force analysis. They demonstrated the influence of forces on heat input, but the relationship with the processing parameters was not exhaustively investigated. Baraka et al. found that material reactions to the tool penetration and advancement are integral information for the online process monitoring and for the dynamic reprogramming of the operative parameters [23]. Similarly, Mishra et al. stated that these aspects are particularly relevant in the current context of the industry 4.0 by indicating their influence on the overall performance of a manufacturing system [24]. The lack of consolidated knowledge in friction stir lap welding of AA2198 alloy is even more evident when dissimilar joints are regarded. As a matter of fact, FSW of 2xxx and 7xxx series has been studied in the last years, but most studies were devoted to well-known alloys, such as AA2024 [25, 26], whereas few reports detailing the FSW of AA2198 with 7xxx series alloys have been published [27]. Similarly, available studies providing a better understanding of force arising during the friction stir welding of AA 2198, even in butt joint configuration, are not exhaustive to the scope of process monitoring. The present paper is focused on the dissimilar FSW of AA 2198 to AA 7075 in the lap joint configuration with the aim to provide a contribution to fill the indicated gap of knowledge. Different processing conditions were explored by varying the main process parameters, namely the tool rotational speed and the welding speed. During the process, selected force components have been acquired using a dedicated device equipped with a load cell. Finally, a detailed microstructure and mechanical characterization was performed by optical and SEM analysis, lap shear testing, and microhardness measurements, attempting to correlate the joint quality with in-process collected data. Under the light of the reported outcomes, the following open questions have been addressed: (i) which is the suitable processing window for the considered welding configuration; (ii) which is the trend of the forces during the process and how processing parameters influences the force profile; (iii) which is the microstructure induced by the action of the tool in correlation with the variation of processing parameters; (iv) how processing parameters and microstructural aspects influences the mechanical properties of the joint.

\section{Materials and methods}

AA2198 T351 $\left(200 \times 100 \times 3.2 \mathrm{~mm}^{3}\right)$ Al alloy and AA7075 T6 $\left(200 \times 100 \times 2 \mathrm{~mm}^{3}\right)$ alloy sheets were used as base materials. The nominal compositions and the mechanical properties of these alloys are reported in [28, 29]. A CNC machine (FAMUP MCX 600) operating in displacement control mode was employed to conduct the FSW tests, by positioning the AA2198 on top and AA7075 on the bottom of the overlap configuration and adopting an overlap length of 25 $\mathrm{mm}$. The adjoining surfaces of both plates were cleaned with a stainless-steel brush and acetone before the welding process. An additional sheet was placed under the AA2198 plate to avoid undesired displacement. The adjoining material was clamped on the backing plate and fixed on a Kistler ${ }^{\mathrm{TM}}$ threeaxis dynamic dynamometer positioned on the machine table, to detect force components. More specifically, the in-plane welding force (hereinafter $\mathrm{F}_{\mathrm{x}}$ ) acting parallel to the welding direction and the downward forging (hereinafter $\mathrm{F}_{\mathrm{z}}$ ) perpendicular to the plane of the sheet were continuously measured during the process. The welding setup is showed in Figure 1.

An H13 steel tool, characterized by concave shoulder and tapered left-hand threaded pin, was used in this work. The tool was kindly supplied by FPT Industrie SPA. Tool dimensions are reported in Figure 1. The selection of tool geometry was based on the following considerations: (i) the tapered threaded pin introduces a vertical component in the stirring action enhancing material flow and (ii) a pin length greater than the thickness of the top plate allows the pin to be plunged inside the bottom sheet providing a weld interface based on mechanical locking [26]. Alternatively, materials joining relies only on the formation of a relatively weaker conversion layer at the interface.

The details of the experimental campaign are given in Table 1. The design of experiment (DOE) is based on the variation of the main process parameters, namely tool rotational speed (TRS) and welding speed (WS). In the same table, the revolutionary pitch, defined as the ratio between TRS and WS, is provided. In each case, the tool was rotated clockwise and tilted $2^{\circ}$ forward to enhance the forging action of tool shoulder. The shoulder was plunged for $0.2 \mathrm{~mm}$ in the top sheet. 
Fig. 1 Friction stir welding setup

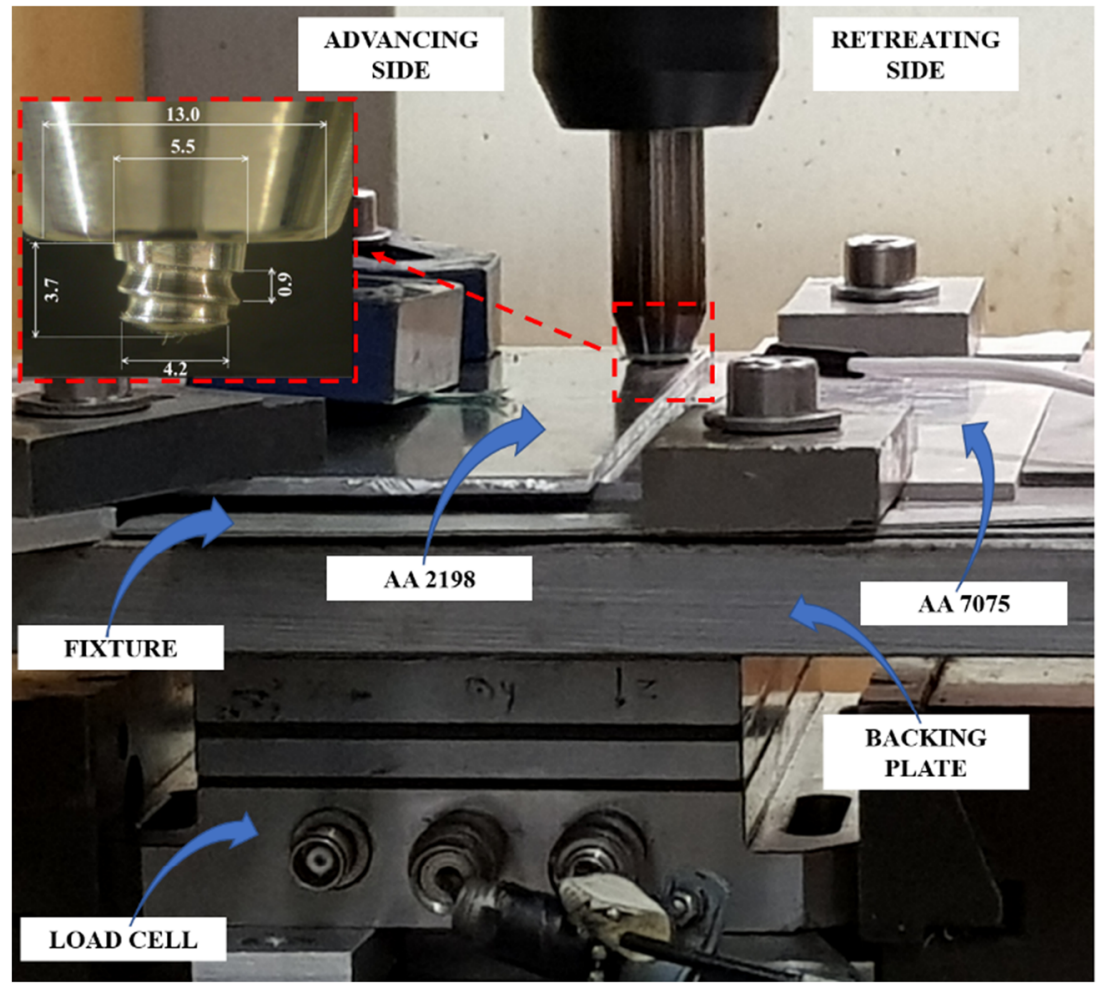

After the joining process, the morphology of the welded crown of each sample was observed and measured, with respect to the relevant features, by means of confocal microscopy (LEICA DCM 3D). From each weld, three metallurgical specimens were extracted for macroscopic, microscopic, and microhardness characterization of the cross section orthogonal to the weld line. The extracted pieces were mounted by using a conductive thermoplastic resin supplied by Struers (Lucite). After that, samples were ground with $\mathrm{SiC}$ papers and then lapped using diamond suspension down to $1 \mu \mathrm{m}$ to achieve a mirror-like finishing for the metallurgical observations and analysis. Samples were etched by using Keller's reagent for $15 \mathrm{~s}$ to unveil the significant metallurgical features. A metallurgical microscope (Olympus GX71) equipped with an Olympus digital camera (XC50) and a scanning electron microscope (Hitachi TM3000) equipped with a National Instruments EDX microprobe (Oxford

Table 1 Inestigated processing parameters

\begin{tabular}{lll}
\hline $\begin{array}{l}\text { Tool rotational speed } \\
{[\mathrm{rpm}]}\end{array}$ & $\begin{array}{l}\text { Welding speed } \\
{[\mathrm{mm} / \mathrm{min}]}\end{array}$ & $\begin{array}{l}\text { Revolutionary pitch } \\
{[\mathrm{rot} / \mathrm{mm}]}\end{array}$ \\
\hline 1200 & 60 & 20 \\
1500 & & 25 \\
1800 & & 30 \\
1200 & 120 & 10 \\
1500 & & 12.5 \\
1800 & & 15 \\
\hline
\end{tabular}

Instrument Swift ED3000) were used to observe the microstructure of the welding zones, and to detect eventual IMCs precipitation. Vickers micro-hardness tests were conducted setting an indentation load of $100 \mathrm{~g}$ for a dwell time of $15 \mathrm{~s}$ by using a Leica QVMHT Hardness Tester. The distance between indentations was equal to $0.5 \mathrm{~mm}$. The mechanical properties of the joints were assessed by lap shear testing. In absence of a dedicated standard defining all prescriptions for lap shear test of friction stir welded joints, the ASTM D1002 standard (Standard Test Method for Apparent Shear Strength of Single-Lap-Joint Adhesively Bonded Metal Specimens by Tension Loading, Metal-to-Metal) was considered as main reference, as indicated also in [30]. Five specimens, $25.4 \mathrm{~mm}$ in width, were cut from each joint, using all the available length $(175 \mathrm{~mm})$. The grip area was defined as $25.4 \times 25.4 \mathrm{~mm}^{2}$, whereas opportune tabs were used to avoid undesired stress components. The sides of the specimens were polished and then painted by using acrylic varnish to obtain a speckle pattern [31]. An MTS Insight universal testing machine was employed to conduct the lap shear test, whereas an industrial uEye camera equipped with a $25-\mathrm{mm}$ objective lens was used to record the failure mode of each sample.

\section{Results and discussion}

\subsection{Forces analysis}

A qualitatively similar trend was detected for the force components $\mathrm{F}_{\mathrm{x}}$ and $\mathrm{F}_{\mathrm{z}}$ for all the performed welding processes. A 
representative plot, related to the $1200 / 60$ welding conditions, is shown in Figure 2.

As intuitive, force components are influenced by the material flow in the region surrounding the tool pin. Boccarusso et al. [32] discussed that the force profiles are strictly dependent on the specific processing stage, namely plunging, dwelling, and welding (or travelling) phases. These stages are described below and are called phase I, phase II, and phase III:

(i) Phase I corresponds to the tool plunging. It starts when the rotating pin approaches the upper surface of the AA2198 sheet (generating a first $F_{z}$ peak, indicated as $A$ in Figure 2), and bring to an end when the top sheet is fully crossed by the pin and the desired plunging depth has been reached. A second $\mathrm{F}_{\mathrm{z}}$ peak (indicated as $\mathrm{B}$ ) has been detected when the shoulder was approaching the top surface and the pin was plunged inside the AA7075 sheet. This second peak results higher than the former one due to the larger contact area between the shoulder and AA2198 surface and the higher resistance of the AA7075 sheet at relatively lower temperature Noticeably, in phase I, the Fx is close to zero. The plunging velocity was defined as equal to the welding speed for each condition.

(ii) Phase II includes a dwelling time of $15 \mathrm{~s}$. A localized rise of the temperature is caused by the rotational movement of the pin and ascribed to the frictional heat. The induced thermal softening of the material implies a reduction in the resistance to tool plunging. Consequently, $\mathrm{F}_{\mathrm{z}}$ decreases approaching a local minimum at the end of phase II.

(iii) During phase III, which represents the actual welding, the tool proceeds along the joint line, promoting a continuous mixing and bringing together the materials. It is visible that, component $\mathrm{F}_{\mathrm{z}}$ initially exhibits a local peak, indicated as $\mathrm{C}$ in Figure 2, before stabilizing on a reasonably steady state value. As expected, at the beginning of this phase, the component $F_{x}$ sharply increases due to the the movement of the tool along the $\mathrm{x}$ direction and inherent resistance to material displacement.

Figure 3 summarizes the values of the A and B peaks (related to the $\mathrm{F}_{\mathrm{z}}$ force component) as well as the steady state values of both components, for all the welded joints. As reasonably expected, the value of the vertical force, $\mathrm{F}_{\mathrm{z}}$, is always considerably major than the in-plane one, $\mathrm{F}_{\mathrm{x}}$.

Collected data clearly pointed out the influence of the processing parameters on the peak values $\mathrm{A}$ and $\mathrm{B}$ exhibited by the component $\mathrm{F}_{\mathrm{z}}$ during the plunging phases. As a matter of fact, increasing the rotational speed involves a higher quantity of frictional heat released at the material-tool interface, causing a more significant material softening. Therefore, smaller downward vertical forces are needed to plunge the tool at the planned depth. Zimmer et al. [33] also observed that the forces are influenced by the processing parametrs and in particular that a lower downward vertical force is required when the heat input is increased. The two peaks, A and B, are roughly of the same magnitude because the mechanical properties of the two aluminum alloys are substantially similar. Boccarusso et al. [32] found a different evidence, i.e., a noticeably difference between the two peaks, in the case of friction stir lap welding of AA6082 aluminum alloy to AZ31 magnesium alloy. Reasonably, this is attributable to the distinct mechanical properties of the investigated materials. Conversely, lower values for $\mathrm{F}_{\mathrm{z}}$ force were detected during the plunging stage lowering the welding speed, since the plunging speed was accordingly reduced. In fact, assuming the rotational speed as a constant, the same amount of heat is generated and dissipated into the material. Obviously, if the penetration of the tool inside the sheets is relatively slower, more time is left to heat diffusion across the thickness, and this leads to a more pronounced softening of the material. Steady state values of both $\mathrm{F}_{\mathrm{z}}$ and $\mathrm{F}_{\mathrm{x}}$ components are plotted in Figure 3 (c and $\mathrm{d}$ ) as
Fig. 2 Representative force profiles, measured adopting TRS $1200 \mathrm{rpm}$ and WS $60 \mathrm{~mm} / \mathrm{min}$

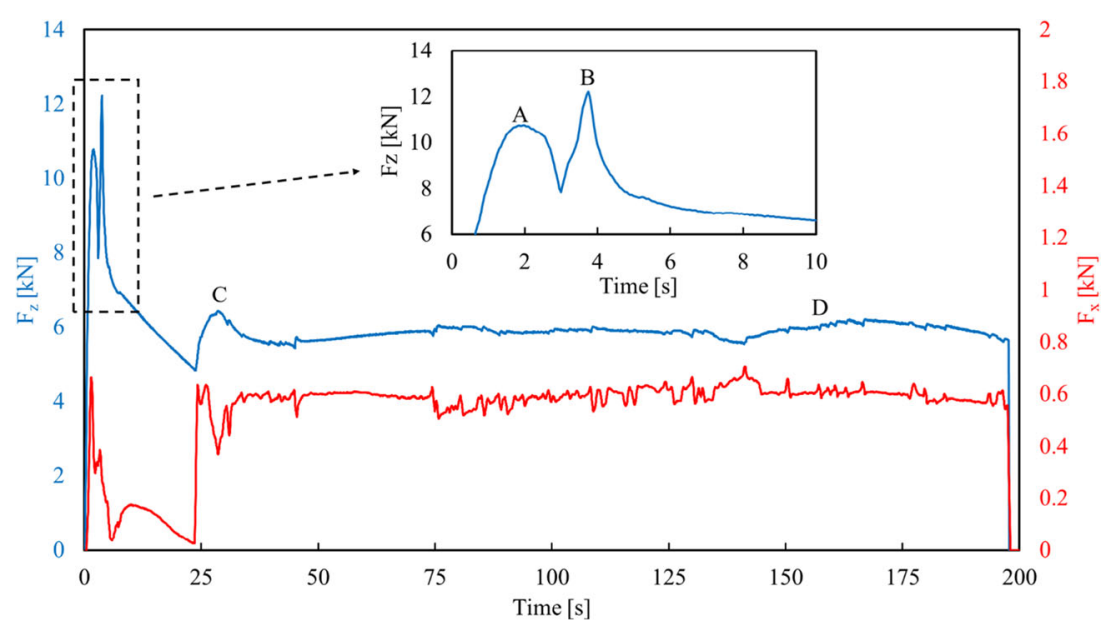



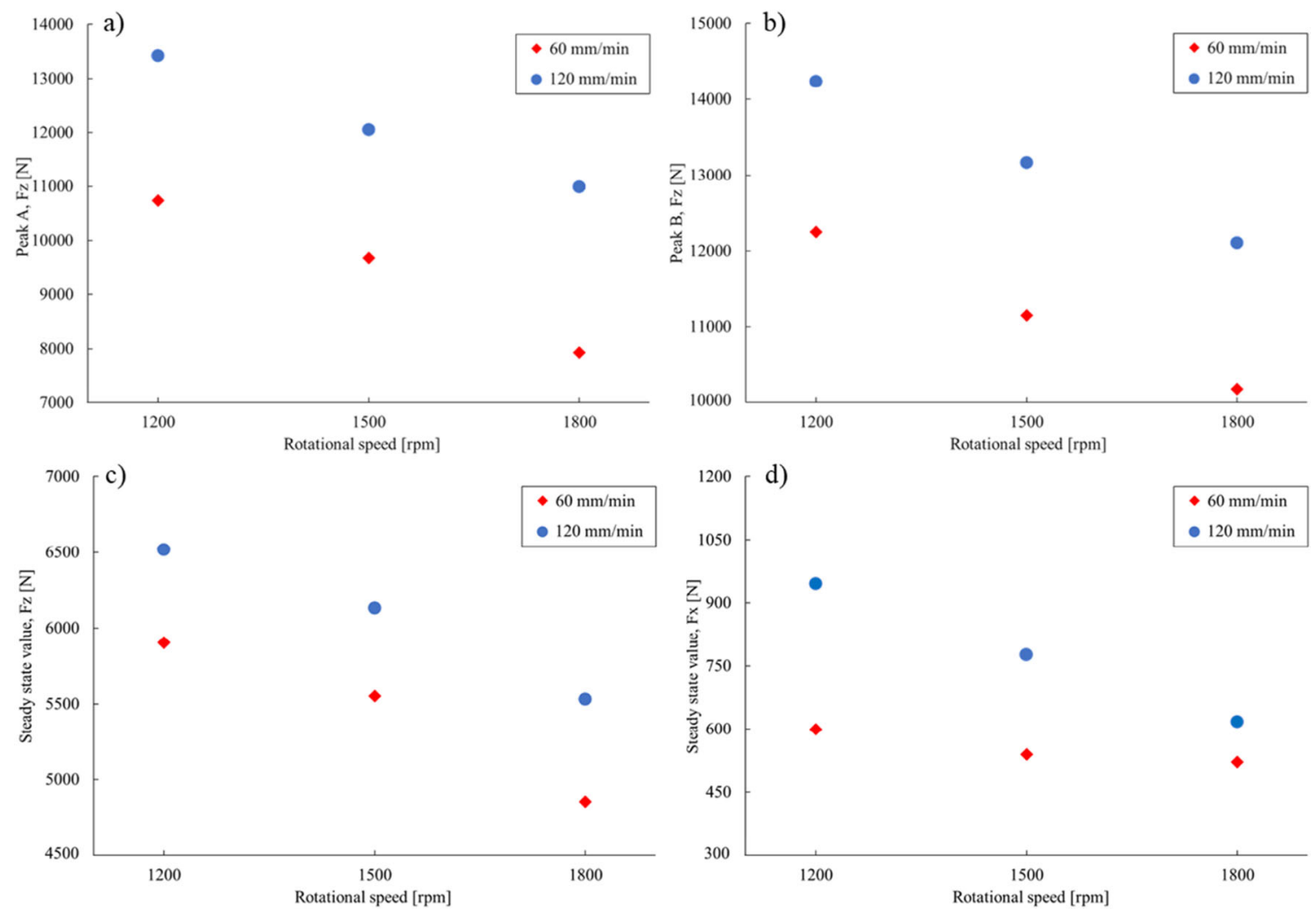

Fig. 3 Peak and steady state values of the forces measured during the welding in all the processing conditions

a function of the processing parameters. Astarita et al. [34] asserted that, referring to the friction stir butt welding, both $\mathrm{F}_{\mathrm{z}}$ and $\mathrm{F}_{\mathrm{x}}$ components present a monotonic increase at higher WS for a fixed TRS and, on the other hand, present a monotonic decrease when increasing the TRS for a given WS. Indeed, softening phenomena are strongly related to the material resistance and flow conditions, whereby the higher the heat input is, the smaller the force results. Similar considerations can be drawn assuming force components variation as a function of the revolutionary pitch. In fact, higher revolutionary pitch involves a higher heat input leading to a more significant material softening and lowering of the forces.

\subsection{Macroscopic and microstructural observations}

Representative images of the top surface of the joints including a macroscopic view of the cross sections are reported in Figure 4. It can be immediately observed that for all the considered combinations of processing parameters, material continuity at the interface between the top and bottom sheets was successfully achieved. Nevertheless, for processing conditions except 1500/60 and 1200/60, internal defects, namely grooves and tunnels according to the nomenclature proposed by Mishra and Ma [35], were detected (highlighted by white arrows in Figure 4). It can be deduced that defect formation in the cross section can be avoided only by adopting revolutionary pitch ranging from 20 to 25 .
Figure 5 represents the microhardness distribution on the welding cross-section. The microhardness contours are reported over the optical microscopy acquisitions of the samples cross-section, after the lapping, polishing, and chemical etching.

From a qualitative point of view, each joint, except the one welded at 1200/120, shows a similar microstructure, characterized by a clearly visible nugget zone (NZ) exhibiting the typical onion ring structure. Also, an evident formation of lateral hooks of AA7075 penetrating within the AA2198 top layer and encapsulating the nugget area is appreciable. The slight plunging of the tool into the bottom sheet, necessary to generate a bonding region, promotes the upward extrusion of the material from the interface toward the stirred zone (SZ). Song et al. [25] highlighted that this vertical flow of material is responsible for the formation of the hook-shaped macrostructure.

A slightly different appearance is showed by the joint welded at $1200 / 120$, representing the processing conditions characterized by the lowest heat input. The onion ring structure is still clearly visible, but, differently from other samples, there is only one short hook in the advancing side. This outcome suggests that the formation of the hooks is ruled by the amount of heat generated during the process and the heat transfer within the material. In concept, hook formation can be considered as a jetting phenomenon, ruled by the plunging pressure and the viscosity of the softened material. 

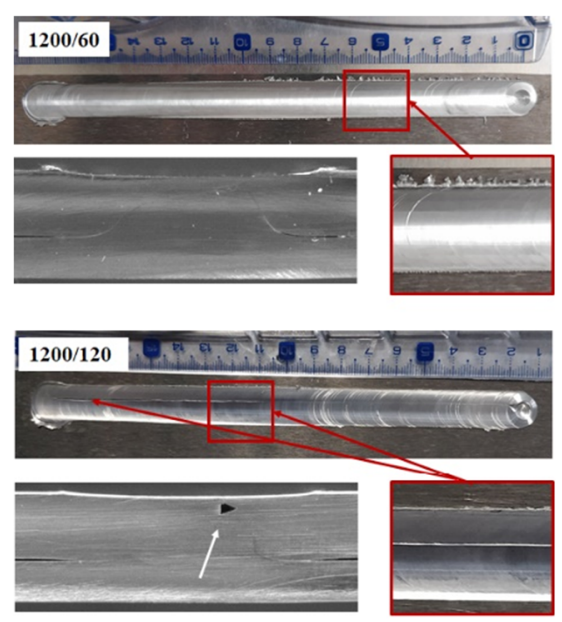
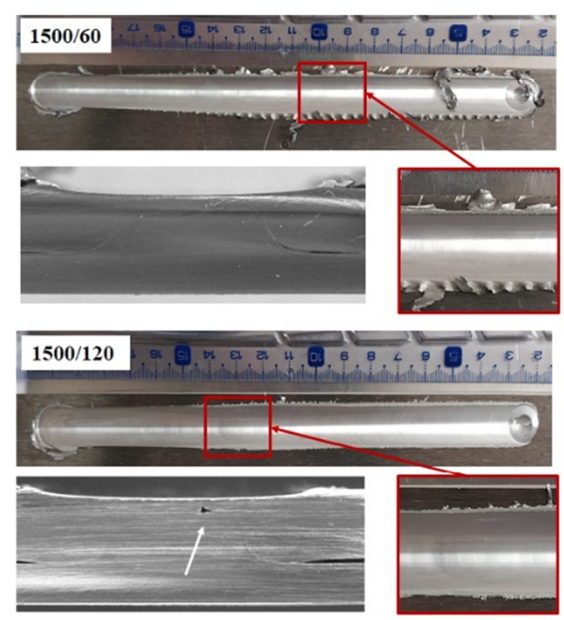
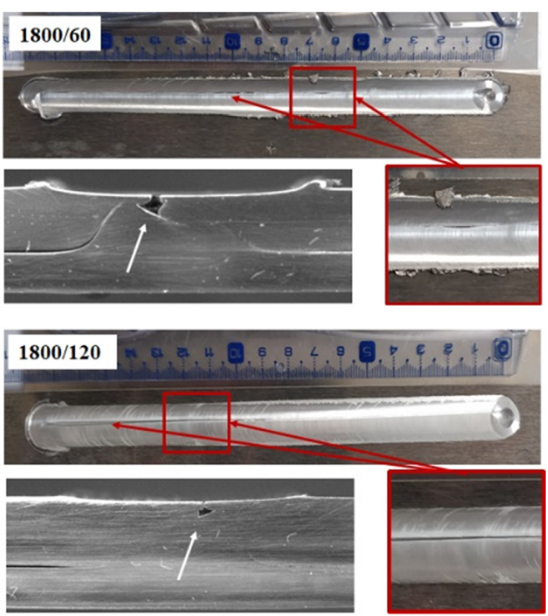

Fig. 4 Cross sections and top surfaces of welded joints, including a close up of the crown (arrows highlight surface and internal defects as tunnel or groove)

The microhardness maps reflect the material flow described in the previous sections. An increase in microhardness was detected in the region of each hook. This evidence is consistent with the SEM observations that showed that hooks are made of recrystallized grains that experienced a severe work hardening. It is also possible to appreciate that the global hardness of the joint increases with the decrease of the TRS, i.e., increase with the decreasing of the heat input. Similar observation involving conventional FSW and relevant global hardness trend was reflected in the investigation conducted by Mehta et al. [36].

In the followings, high magnification micrographs, captured with both optical microscope and scanning electron microscope, are provided to highlight the microstructures established by the process. Figure 6 provides some details of the metallurgical features detected in the observed cross section. In particular, the joint welded at 1500/120 was here used as representative one in the interest of brevity.
Recalling the standard terminology used in friction stir welded joints, the nugget zone (NZ) is defined as the region of the weld bead that experienced a full recrystallization due to the action of the tool. The thermomechanical affected zone (TMAZ) is the region of the weld bead, adjacent to NZ, where the grains appear highly deformed but not fully recrystallized [10]. By adopting this classification, a very interesting NZ can be identified. Fully recrystallized zones can be observed in the center of the joint, where the onion ring structure made of AA 2198 is well evident (see Figure 6e and Figure 6d), at the boundary between AA2198 and AA7075 (Figure 6f); in the hook region in the retreating side (see Figure 6a and Figure 6h); and, finally, in the flow arm region (see Figure 6c). From this observation, it can be claimed that the NZ is made of four different subzones: the onion ring region (made of AA 2198), the flow arm region (made of AA 2198), the inner part of the hooks, i.e., the side of the hooks adjacent to the onion rings, (made of AA7075), the upper part of the
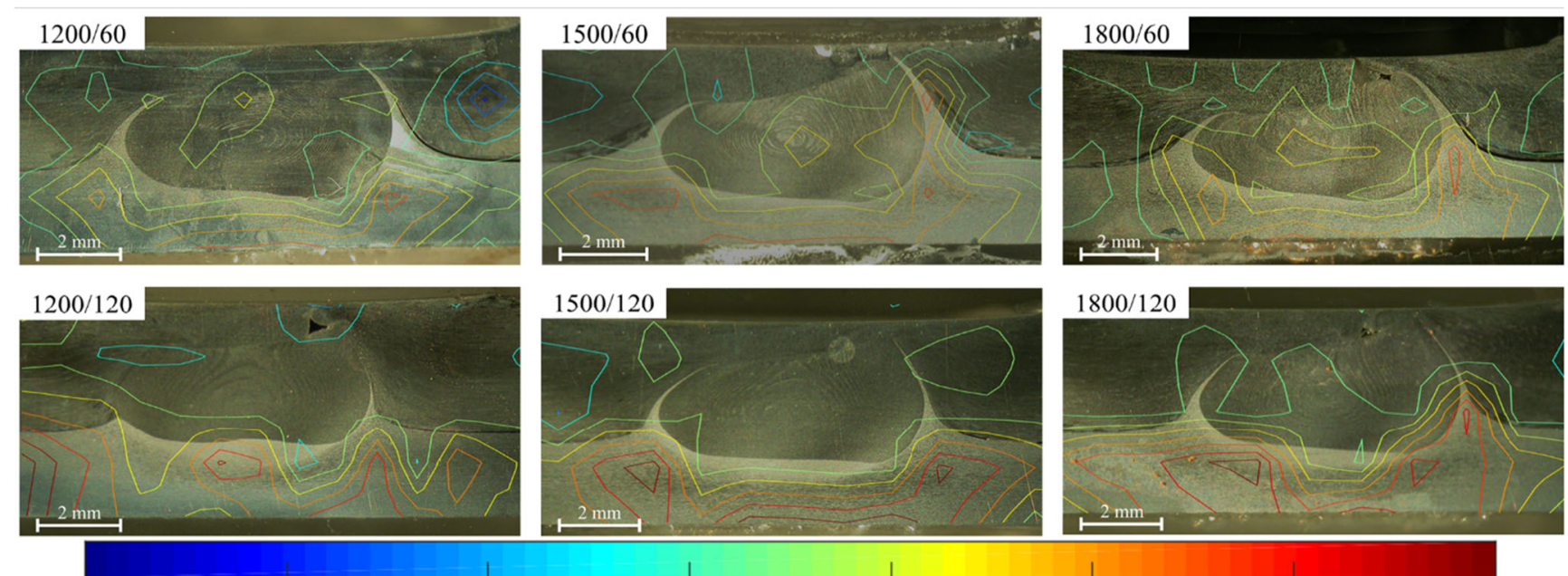

70

80

90

100

HV 0.1

110

120

130

140

Fig. 5 Optical observation of the polished and etched cross section, and representation of the microhardness distribution (advancing side on right hand side) 

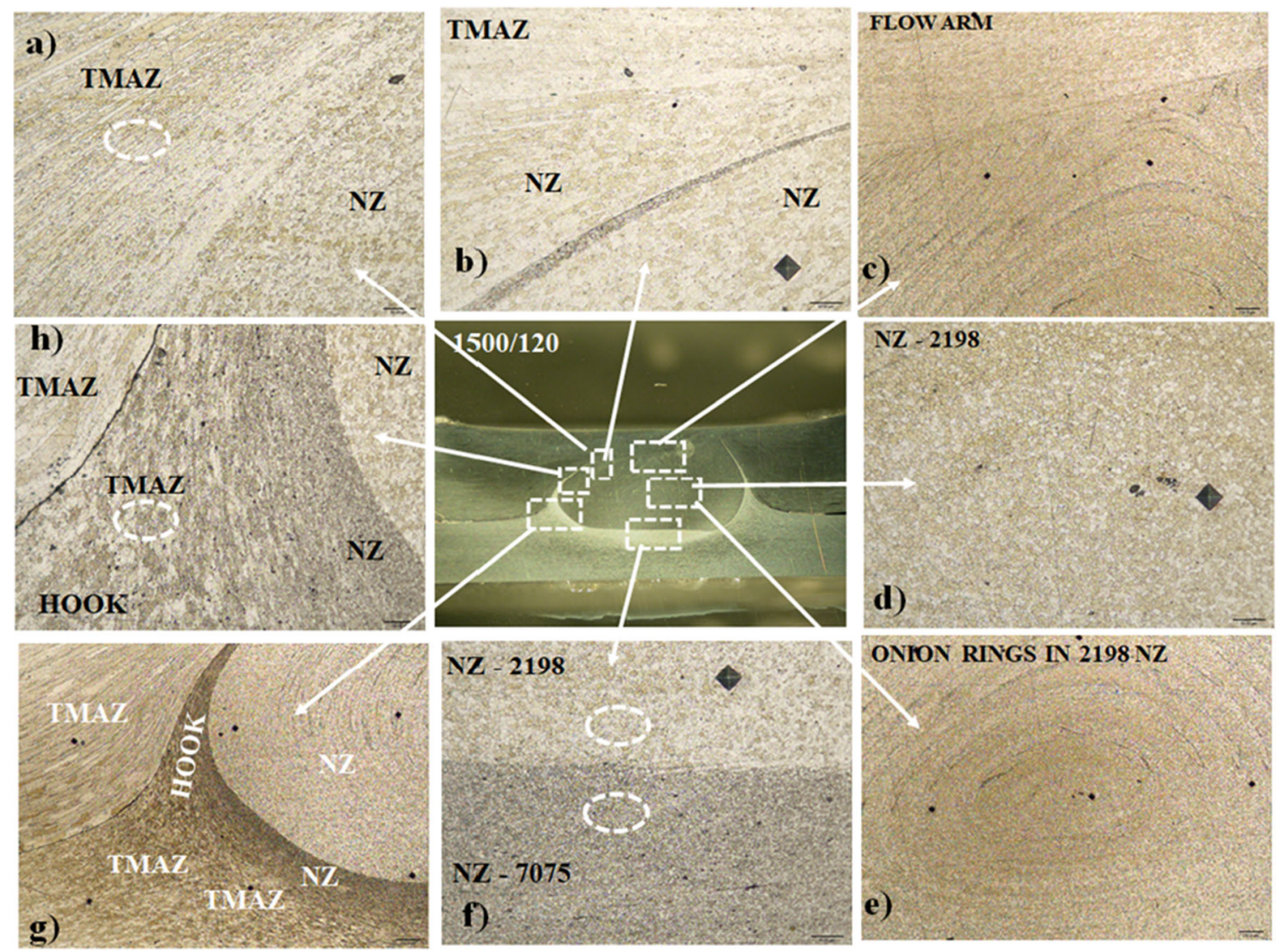

Fig. 6 High magnification micrographs of the 1500/120 joint depicting the different metallurgical zones produced by the welding process

AA7075 sheet. In Figure 6 b, the very thin tip of the hook, surrounded by fully recrystallized AA2198 grains, is visible, supporting the evidence that the hook penetrated in the AA2198 nugget zone. On the other hand, Figure $6 \mathrm{~h}$ points out that the root of the hook is in between the fully recrystallized grains of the NZ and the stretched grains of the TMAZ. Interestingly, the hook itself seems to be made of two different regions, which experienced a full recrystallization or a grain stretching, respectively. Concerning the TMAZ, two different areas have been observed, constituted, respectively deformed grains of AA2198 (Figure 6a) and of AA7075 (Figure 6g, h). The heat affected zone (HAZ) cannot be easily identified at these magnifications since it is only characterized by a different distribution of the second phase back particles, as also in [37]. This peculiarity has been observed for several aluminum alloys.

The presence and morphology of the hooks significantly influence the mechanical strength of friction stir welding lap joints; nevertheless, there is no agreement about the actual role played by this feature. According to [26], there are two main factors affecting the tensile strength of FS welded lap joints: effective sheet thickness (EST) and the sheet interface shape (hooking). Dubourg et al. [1] reported that the material hooking is crucial for the mechanical properties of AA 2024 and AA 7075 friction stir welded lap joints. Naik et al. pointed out that the hook represents an interpenetrating feature creating a mechanical interlocking conditions that enhances the tensile strength of the joint [38]. On the other hand, Chowdury et al. reported that hooks materialize preferential paths for crack propagation, negatively affecting the resistance of the joint [39]. Detailed high magnification micrographs for the hook in the advancing side and in the retreating side have been reported in Figure 7 and Figure 8. From those figures, it is immediate to observe that both hooks are made of fully recrystallized equiaxial and fine grains. Furthermore, hooks are clearly distinguished from the onion rings region, which is made of AA2198, suggesting that the hook formation is related to the upstream material flow of AA7075 from the bottom sheet.

The present study also highlighted the formation of a crack in the advancing side between the hook and the AA2098 TMAZ (see Figure 7) while complete material continuity was detected between the aforementioned hook and the nugget zone (Figure 8). This occurrence can be explained taking account of the material flow leading to the hook formation and considering that, with reasonable approximation, i.e., neglecting the tilt angle $\left(2^{\circ}\right)$, the tool axis is perpendicular to the faying surfaces of both sheets. This geometrical condition prevents an effective breaking action of the oxide layers at the 


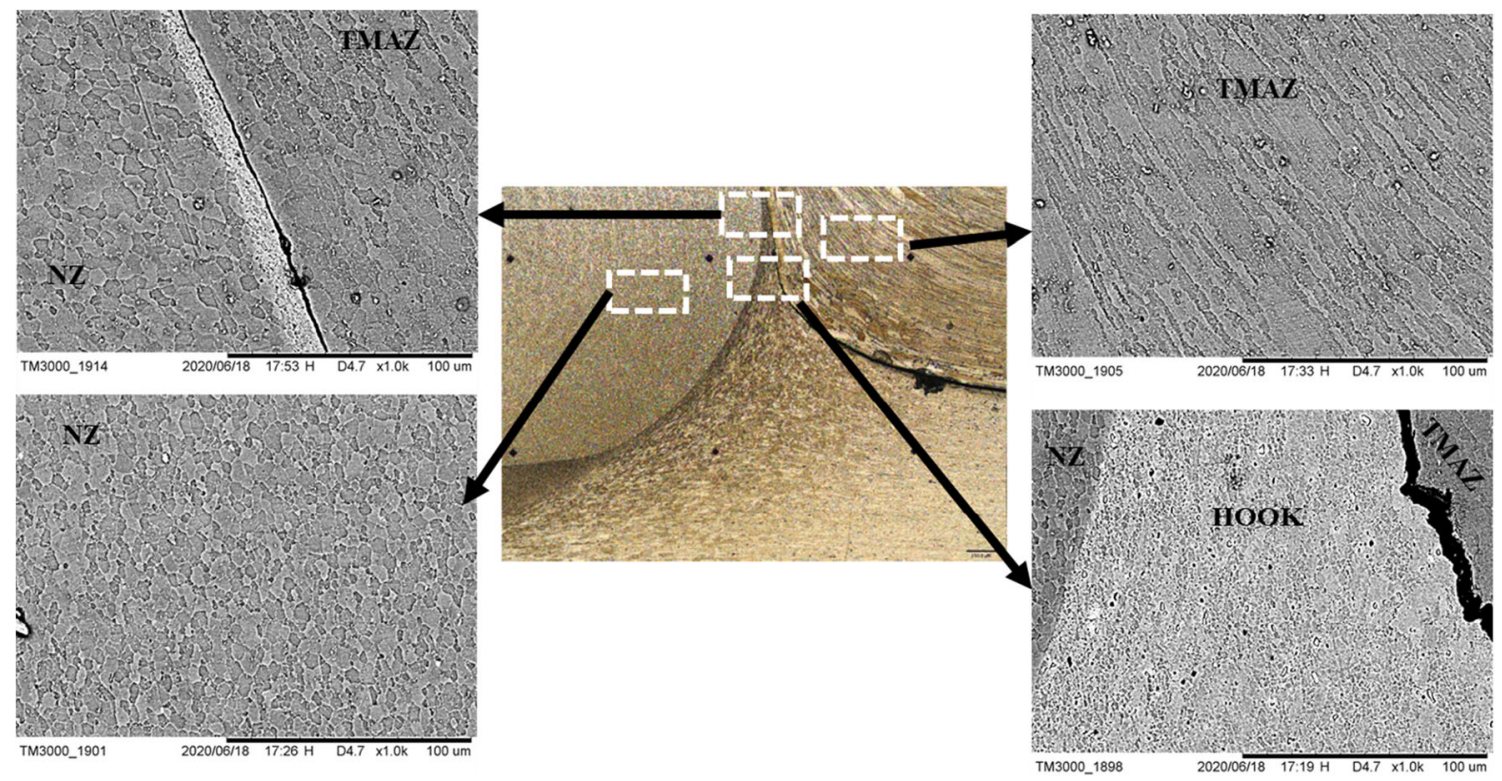

Fig. 7 High magnification images of the hook in the advancing side of the joint

sheet interface, differently from what is typically observed in friction stir butt welding and this in turn obstruct the achievement of a complete material continuity. The hook formed in the retreating side showed a similar evidence, but the crack is extremely narrow and is not continuous if compared to the previous case, suggesting the creation of a weak region in the advancing side of the joint. To summarize, it is possible to claim that hooks exhibit a crack-like unbonded interface generated by the tool during the stirring from the original faying surfaces on both the advancing and retreating sides. The difference between the transition from the hook to the surrounding region in the advancing and retreating side has been related to the material flow pattern promoted by the stirring action of the tool. In fact, the material is continuously transferred from the advancing to the retreating side, inducing a compression and crack closure effect in the retreating side and generating a lack of material in the advancing side. The hook morphology is closely related to the material flow and deformation as well, consequently, some differences are detected comparing the hook shape and size in the advancing and retreating sides.

Figure 9 reports the height of the hook, in both advancing and retreating sides, as a function of processing parameters. Indeed, the plastic flow of the material is asymmetric on the two sides, being rotational and welding speed concordant in the AS, where a higher hook is formed, but opposite on RS,
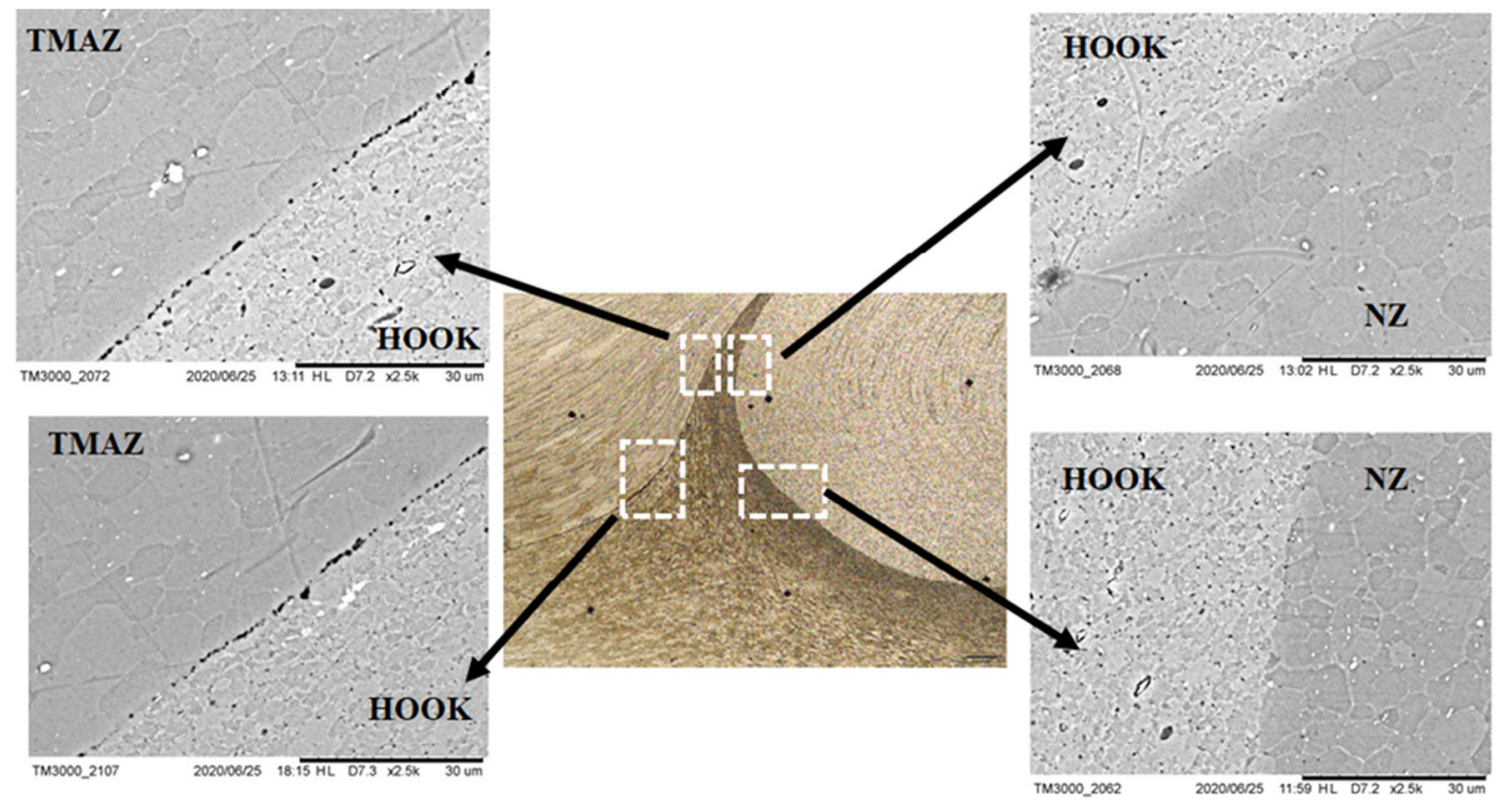

Fig. 8 High magnification images of the hook in the retreating side of the joint 

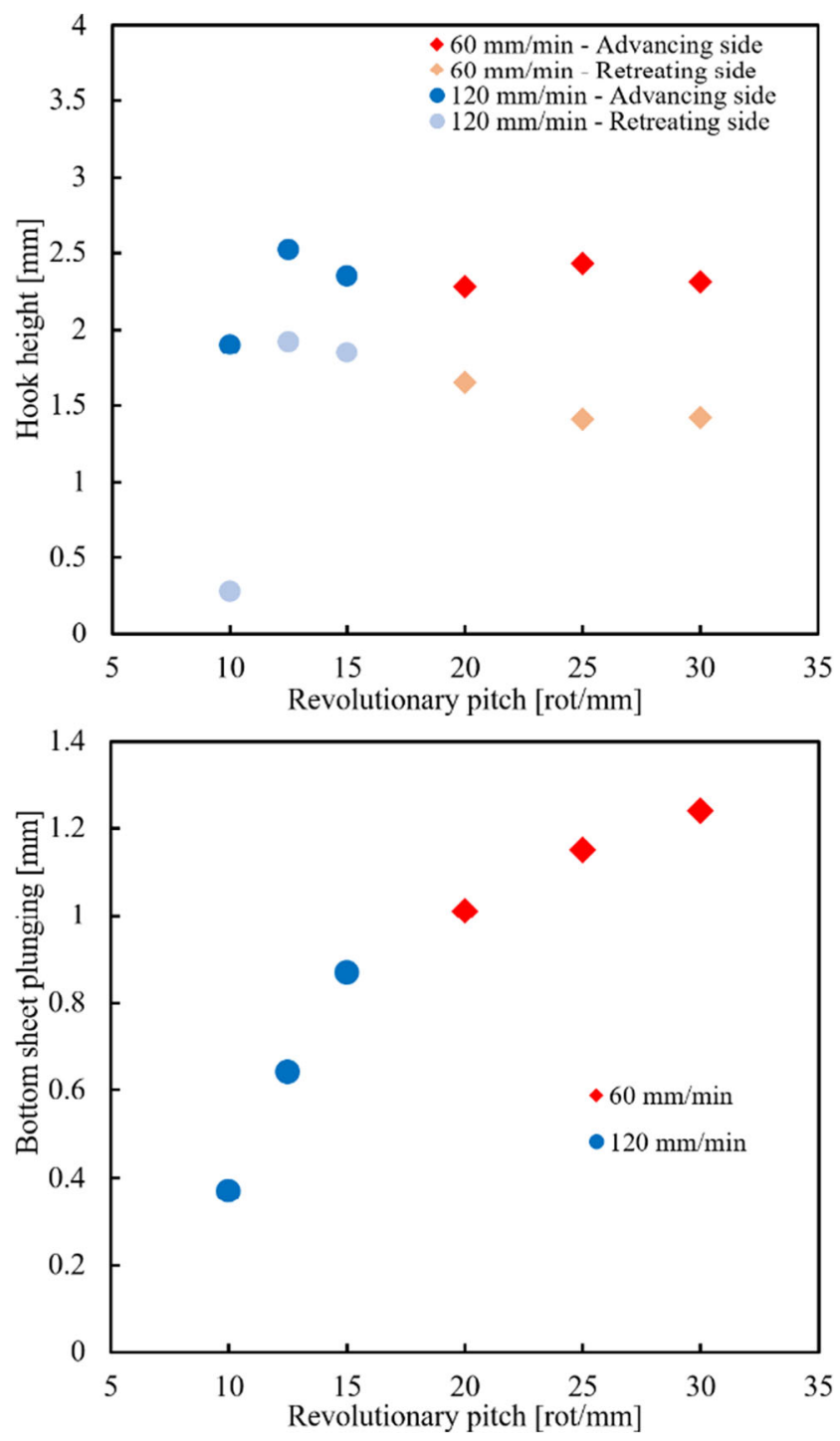

Fig. 9 Geometrical details of the welding features (hook height on top and bottom sheet plunging on bottom) as a function of the revolutionary pitch

exhibiting a slighter smaller hook. What is more, being flow velocities influenced by the processing parameters, an obvious influence on hook height is expected. The influence of process parameters on the hook height was not definitely clarified. In fact, the joint welded using the lower heat input (1200/120, corresponding to a revolutionary pitch of 10) showed the lowest values of the hook height (the retreating side hook was almost absent). Then, a sharp increase in the hook height was found for revolutionary pitch equal to 12.5 (1500/120), followed by a decrescent trend. Consequently, a clear correlation between hook height and heat input was difficult to be highlighted. From the analysis of the cross sections, reported in Figure 5, it can be claimed that also the width of the hook was influenced by the process parameters. As an interesting outcome, the maximum measured hook height was associated to the joints welded adopting $1500 \mathrm{rpm}$ as TRS; apparently, a further increase of the TRS led to the formation of a thicker but shorter hook. The TRS increase carried out a consequent rise in the heat input and a more pronounced softening of the material.

The bottom sheet plunging, defined as the maximum depth reached by the NZ underneath the interface between the two sheets to be welded, was found to increase with the increase of the heat input. Babu et al. [40] also showed that an higher heat input implies the widening of the recrystallized NZ toward the bottom sheet.

High magnification microstructures detected the different zones of the welding are given in Figure 6.

The SEM micrographs of the base materials (BM) in both the alloys (Figure 10a and Figure 10d) show a pancake microstructure typical of rolled products, the grains are flattened and stretched along the rolling direction. Some precipitates, easily attributable to the heat treatment used for the BM, are also evident, in particular for the AA7075 alloy, coherently with the different strengthening mechanism.

Figure $10 \mathrm{~b}$ and Figure $10 \mathrm{e}$ show the micrographs of the TMAZ of both AA2198 and AA7075, as detected by SEM observations in the spots indicated in Figure 6 a and Figure 6 h. Stretched, highly deformed and partially recrystallized grains are clearly visible. Furthermore, the grain size appears to be in nearby range for the two alloys. As evident, grains were stretched following the material flow, so along the mixing pattern imposed to the material by the stirring action of the tool.

In Figure $10 \mathrm{c}$ and Figure $10 \mathrm{f}$, SEM micrographs taken in the fully recrystallized zone are reported. Both AA2198 and AA7075 fully recrystallized grains are equiaxed and refined with respect to the BM structure, as observed also elsewhere [41], whereas AA7075 grains appear smaller than the AA2198 ones. This evidence can be explained recalling the recrystallization laws, enunciated by Cahn and Haasen [42], stating that the final grain size is ruled by (i) the initial grain size, (ii) the amount of plastic deformation experienced by the material, (iii) the local temperature experienced during the deformation, (iv) the duration of the exposure at recrystallization temperature or above, and (v) the properties of the material. In fact, the higher the strain rate, the lower the recrystallization temperature; therefore, for a given temperature cycle, higher strain rate implies a more prolonged exposure to temperature exceeding the recrystallization condition [43]. In the investigated case, the two alloys exhibited a very similar initial grain size; nevertheless, the material of the bottom sheet (AA7075) experienced lower temperatures and a lower amount of plastic deformation during the welding process. Zhou et al. [44] discussed that during hot forming processes, such as friction stir welding, aluminum alloy is liable to undergo dynamic recrystallization (DRX), which affects the crystallographic texture and thus mechanical properties. Kim and Yoo [45] demonstrated that the occurrence of DRX leads 

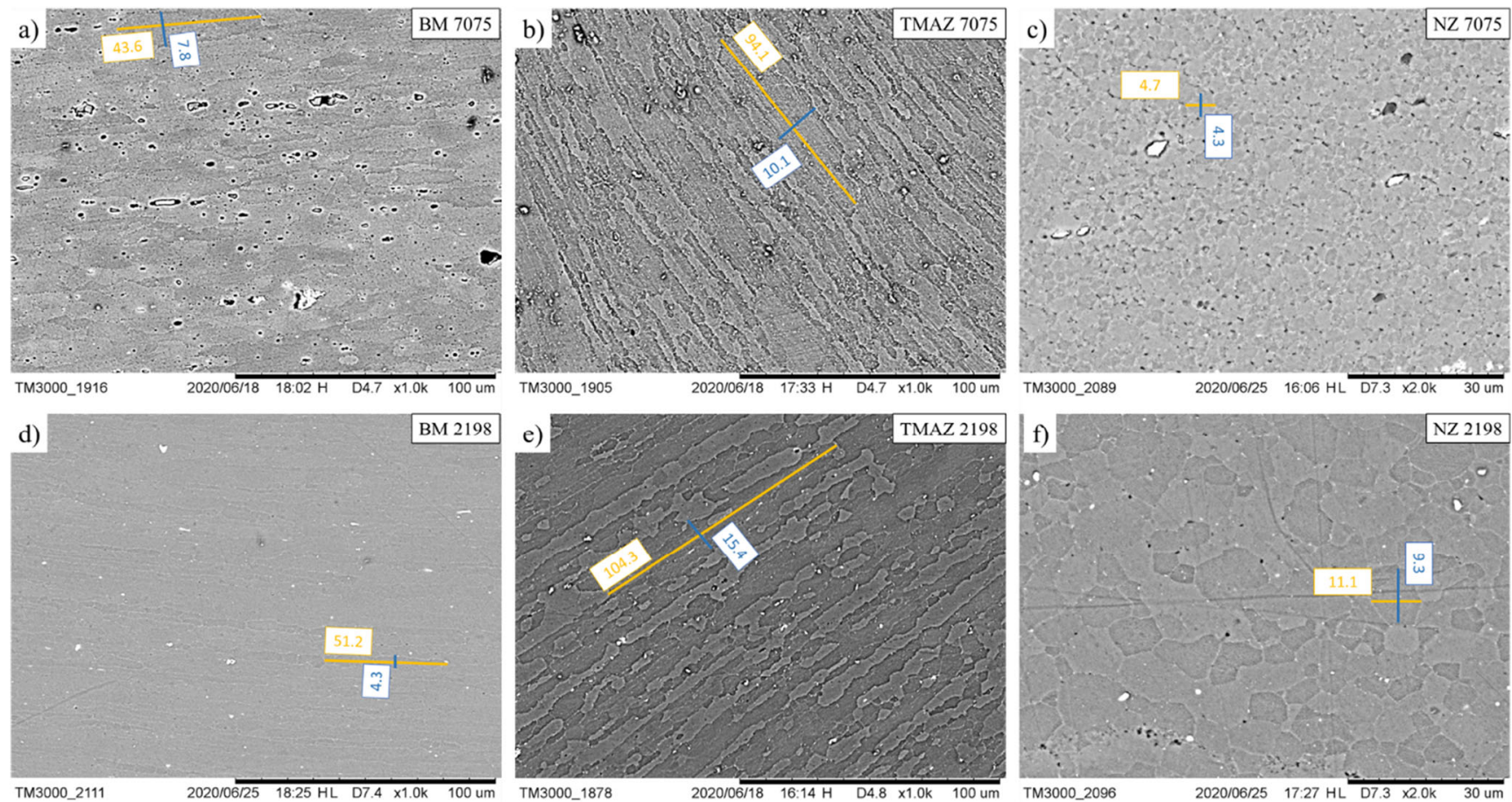

Fig. 10 SEM micrographs of the grains structure of the AA 7075 at the BM (a), the TMAZ (b), and the NZ (c), and of AA 2198 at the BM (d), the TMAZ (e), and the NZ (f)

to the formation of refined equiaxed grains. DehghanManshadi et al. [46] proposed a general descriptive model for DRX where it was stated that the nucleation of DRX grains can start at a critical strain which is a function of initial microstructure and deformation conditions (i.e., temperature and strain rate). Then, the evolution of DRX microstructure can proceed further by increasing deformation and through the formation of an equiaxed, refined microstructure. Ueki et al. proved that both temperature and strain rate, as well as the amount of plastic deformation, have a pronounced influence on the final DRX structure [47]. Furthermore, for a metal material, a pronounced interaction between microstructure evolution and mechanical property exists during a plastic forming process, so the occurrence of DRX and its understanding is fundamental to better understand the whole process. To date, there are no detailed papers describing the DRX behavior of AA2198 alloy during plastic deformation. Some considerations can be drawn following the work conducted on AA2024. Zhang X. et al. [48] studied the axial compression of AA2024 billets by varying temperature and strain rate. They demonstrated that the temperature governs the atomic diffusion and the driving force of dislocation migration while the strain rate controls the dislocation density and the accumulation energy of the grain boundary; they observed that the recrystallization temperature ranges from 523 to $723{ }^{\circ} \mathrm{K}$ depending on the strain rate and the initial microstructure. Quan et al. [49] carefully studied the general recrystallization mechanism and the influence of strain, strain rate, and temperature on DRX behavior of as-extruded AA7075 aluminum. They also proved that the recrystallization temperature is depending on strain rate and initial microstructure, a reasonable range for this temperature was $573-723^{\circ} \mathrm{K}$.

As far as the materials involved in this investigation are regarded, it should be considered that the dynamic recrystallization temperature of AA7075 is slightly higher than AA2198, and that the latter one was further reduced by the relatively higher strain rate, explaining the more refined grain structure induced by the welding process in the AA7075 sheet.

\subsection{Lap shear test}

In this paragraph, results provided by lap shear testing are discussed. Load-displacement curves, measured for all joints, are reported in Figure 11, while images of the fractured specimens are given in Figure 12.

Satisfactory repeatability was found for all the processing conditions. Two branches can represent the trend of loaddisplacement curves. The former is quite linear, with a slope representing the initial linear stiffness of the joint. The latter, at first almost linear even if with a different slope from the first branch, shows the effects of plate element plasticization and bending occurrence due to progressive specimen fracture. This tensile behavior is more evident in the specimens presenting higher hooks. All the specimens presented a progressive increase of load up to final sudden failure, except some that highlighted a saw tooth load-displacement pattern. In this case, the failure mechanism of FSW joints was associated to 

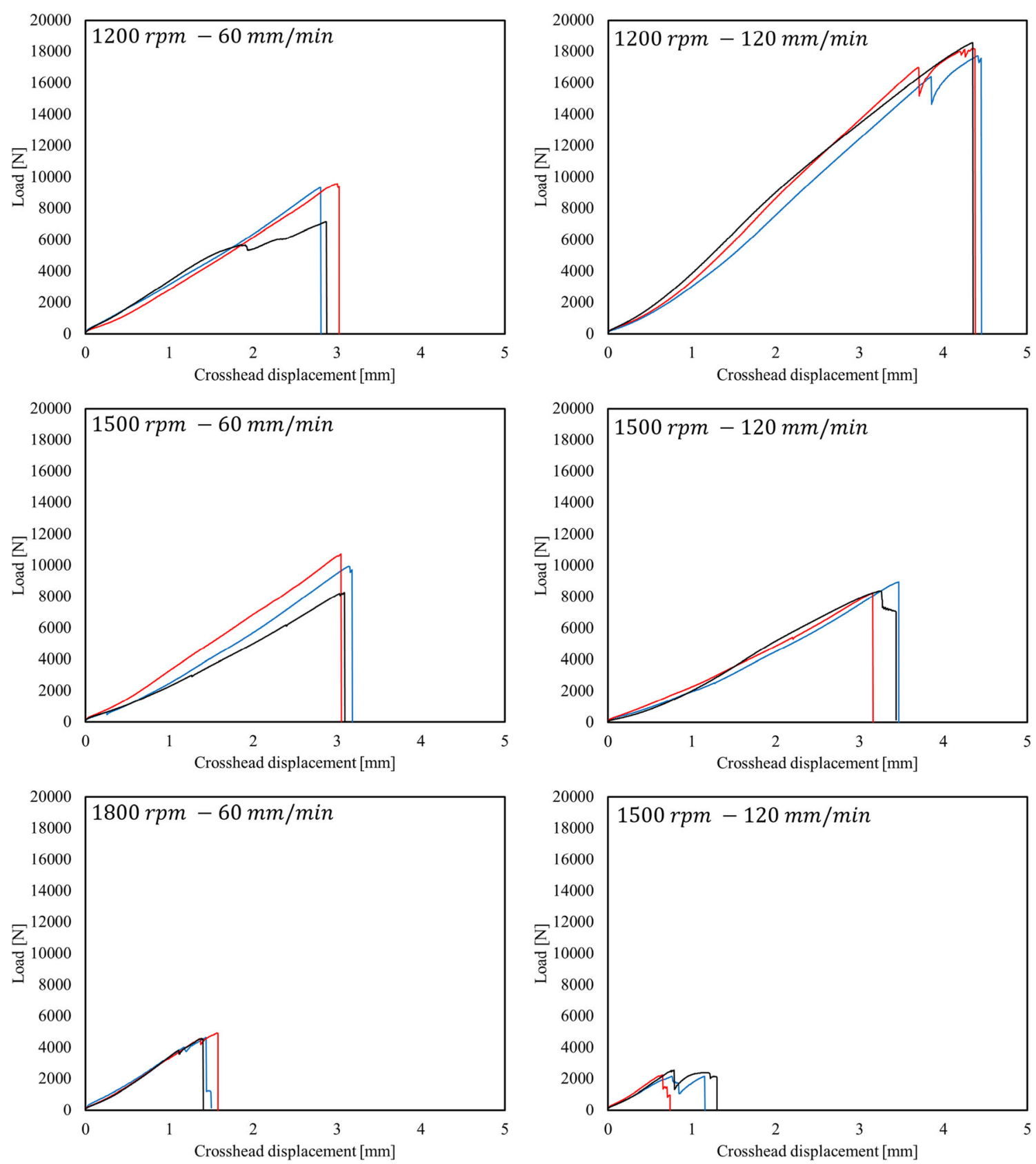

Fig. 11 Load - displacement curves measured during the lap shear tests

the separation of plate elements along the interface surface. Interestingly, the highest tensile properties were exhibited by the joint 1200/120, independently of the internal tunnel, see Figure 4. It should be noted that for this joint, an evident hook in the advancing side was not detected, supporting the thesis of the detrimental effect played by the hook on the mechanical behavior of the joint. Furthermore, it is worth noting that the influence of the hook is dominant with respect to the other internal defects.

A representative failed sample per each set of welding parameters is shown in Figure 12. Two distinct failure modes were observed. Mode A corresponds to tensile fracture starting from the crack at the tip of the hook on AS, propagating upwards along the cracked interface between the hook and the TMAZ and finally fracturing the SZ at the interface between the onion ring zone and the flow arm. This fracture mode was exhibited by all the joints, being the joint $1200 / 120$ the only exception. This joint showed a shear fracture mode (B), where the failure occurs along the original lap interfaces of the two sheets. It is worth noting that the $1200 / 120$ joint is the one exhibiting a negligible hook formation. The joint that failed with the mode B showed the highest ultimate load, further supporting the hypothesis of the negative role of the hook with respect to the mechanical strength. 

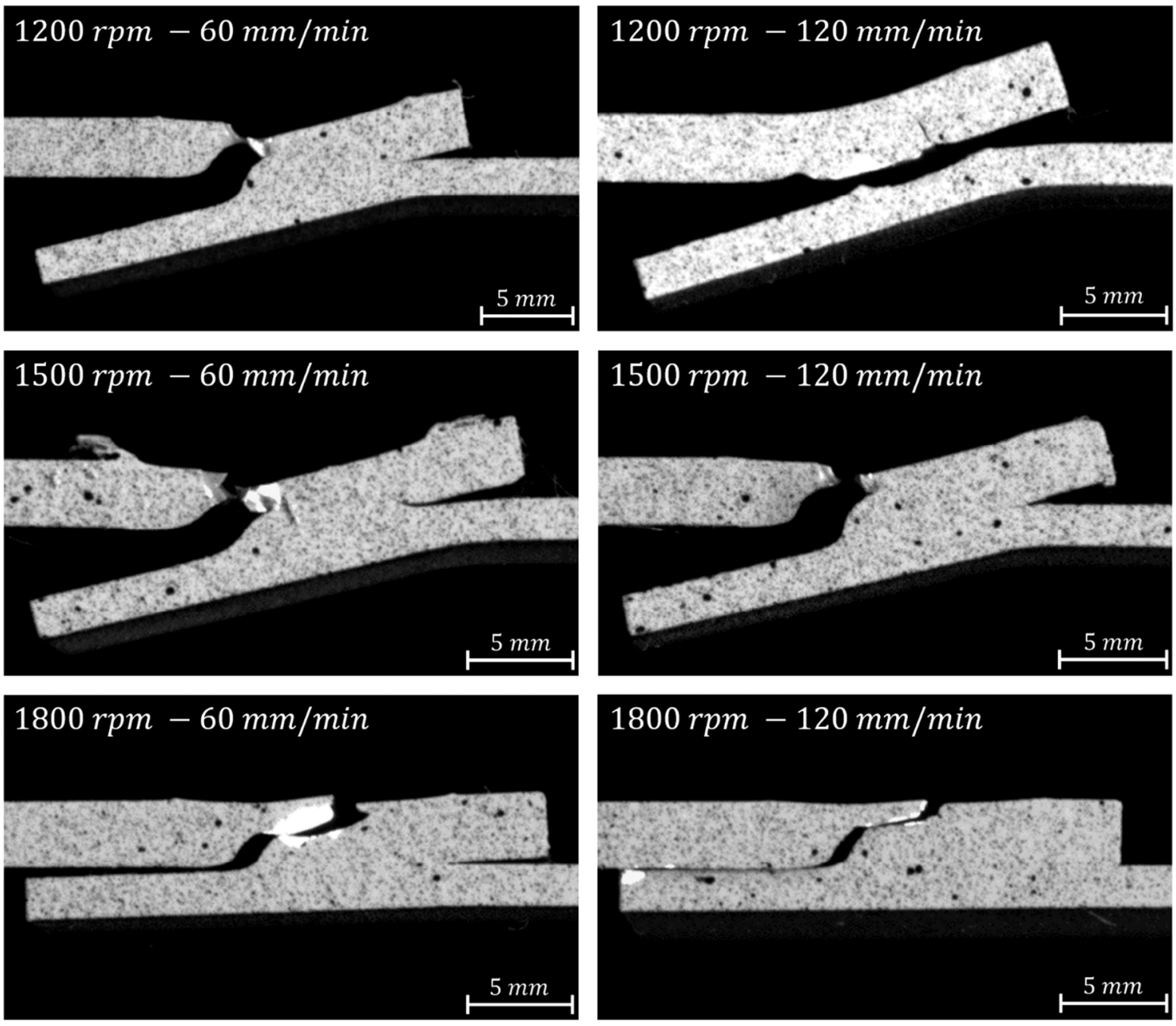

Fig. 12 Photographs of the fractured specimens, evidencing the crack path and failure position (advancing side on the left)

The effective sheet thickness (EST) was firstly introduced by Reynolds and Cederqvist [50] and then defined by Fersini and Pirondi [51] as the residual thickness of the loaded sheet in correspondence of the hook. According to Cao and Jahazi [52], EST represents the minimum distance between any unbonded interface and the top surface of the upper sheet or the bottom surface of the lower sheet. It is mentioned that major EST corresponds to higher mechanical properties of the joint. In this work, following the work done by ShiraziKheirandish-Pouraliakbar [53], the EST was obtained as the difference between the thickness of the top sheet and the height of the hook, as measured on the advancing side. Given the EST, the shear strength $S$ can be calculated as per following equation:

$S=\frac{\mathrm{UTL}}{\mathrm{EST} \cdot W}$

being UTL the ultimate tensile load and W represents the width of the specimen. Figure 13 reports the lap shear strength provided by the above detailed calculations.
The higher lap shear strength was exhibited by the joints welded adopting a TRS value of $1500 \mathrm{rpm}$, while the higher failure load was shown by the 1200/120 joint. This occurrence has been explained considering that joints welded at $1500 \mathrm{rpm}$ were free from internal defects, independently of the welding speed, while 1200/120 joints showed an internal tunnel. Interestingly, while the load at failure provides information regarding the strength of the joint, the shear strength provides useful information about the eventual presence of internal defects.

Attempting to a correlation between lap shear strength, failure mode, and position, the following considerations can be drawn. For samples failed according to fracture mode A (all samples except $1200 / 120$ joint), lap shear strength initially increases with the increase of TRS from 1200 to $1500 \mathrm{rpm}$. The crack followed the hook, leading to the final rupture in the advancing side of the specimen, suggesting a good material continuity between the NZ and the flow arm. On the other hand, increasing the TRS from 1500 to $1800 \mathrm{rpm}$, the opposite variation was observed leading to a reduction of all the 


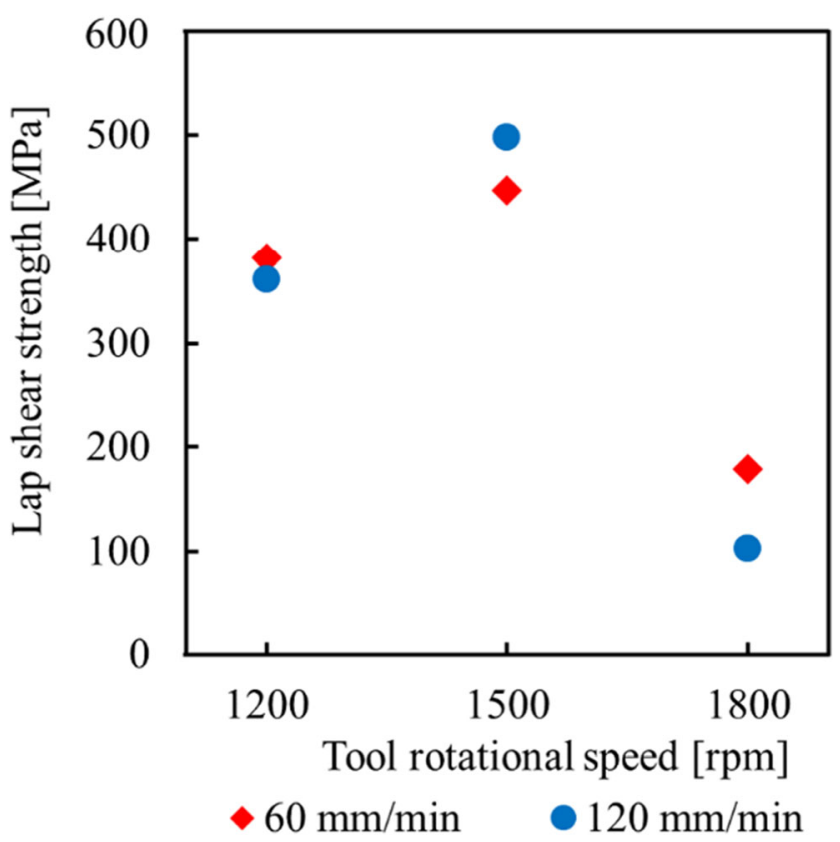

Fig. 13 Lap shear strength variation with welding parameters

mechanical properties. Looking at Fig. 12, it can be seen that the crack started, as for other joints, in the advancing side but easily propagated following the boundary between the NZ and the flow arm. At TRS $1800 \mathrm{rpm}$, it appears that the relatively higher heat input induces an imperfect metallurgical continuity between the NZ and the flow arm created a preferential path for failure even at lower loads, with the final rupture shifted toward the retreating side. As far as 1200/120 joint is regarded, different considerations can be drawn. As a matter of fact, for this combination of processing parameters, the relatively lower heat input and weaker material stirring provided a less evident hook formation and a good metallurgical continuity between the NZ and the flow arm. Consequently, failure mode $\mathrm{B}$ was established, with the crack propagating along the boundary between the NZ and the lower sheet.

Summarizing, the lap shear strength peaked at TRS 1500, and this behavior has been motivated considering physical phenomena occurring during the welding. To achieve a satisfactory mechanical bonding, a certain amount of energy is required to activate the mechanisms (i.e., diffusion, mechanical interlocking, stirring, and remixing of the material) responsible for the metallurgical bonding, meaning that a minimum amount of heat input is required. This justifies the initial increase of the lap shear strength with the increasing of the heat input. Conversely, at higher heat input, other phenomena, such as grain coarsening as well as formation and redistribution of precipitates, are activated, inducing a reduction of the mechanical properties of the joint. Cavaliere et al. [54] also found that the excessive increase of the heat input is detrimental to the mechanical properties of the joint, leading to the claim "the colder the better". In the investigated case, a more significant influence of the TRS, rather than the WS, on the mechanical strength was found.

\section{Conclusions}

Taking into account what herein reported and discussed, the following conclusions can be drawn, attempting to provide some answers to the questions formulated in the introduction of the manuscript:

- The feasibility of the dissimilar joining by friction stir welding of AA 2198 to AA 7075 in single lap joint configuration has been demonstrated for different processing conditions. Internal and surface defects (mainly grooves and tunnels) were found for all the welds produced with an advancing speed of $120 \mathrm{~mm} / \mathrm{min}$ and for the samples processed adopting tool rotational speed of $1800 \mathrm{rpm}$, but a processing window leading to sound joints has been framed and clearly defined.

- Force trend varies during the plunging, dwelling, and travel phase, exhibiting several peaks. Forces increase when decreasing the heat input, i.e., when increasing with the increase of the welding speed and with the decrease of the tool rotational speed. The recorded values of the Fz were always higher than the ones recorded for the Fx.

- An onion rings structure, made of recrystallized grains, was clearly visible in the nugget zone. The nugget zone was constituted by very thin and fully recrystallized equiaxial grains, whereas a more significant refinement was found for the grains of AA7075. Grain refinement was detected also in the flow arm. Hooks were formed in both the advancing and retreating sides, due to the upward flow of AA7075 from the bottom plate. Thermomechanical affected zones, made of highly deformed and partially recrystallized grains, were also identified.

- Single lap shear tests highlighted that the presence and size of the hook, rather than internal defects, are the main factor ruling the failure load. The achieved result supports the hypothesis, already claimed in literature, that the hook has a detrimental influence on the strength of the joints, creating de facto a preferential path for the crack propagation. Furthermore, lap shear strength exhibited a nonmonotonic peak, initially increasing and then decreasing with the TRS. A less significant influence of the WS was observed.

- The microhardness map reflected the different metallurgical zones observed, whereas higher microhardness values where measured in correspondence of the highly deformed and recrystallized grains of the hooks. The microhardness values measured in the nugget zone were slightly higher than the ones of the BM, whereas lower values 
where associated with the heat affected zone. As a general trend, the hardness increases with the decreasing of the heat input, consistently with what typically happens in FSW.

Acknowledgements The authors gratefully acknowledge Eng. Ilaria Coppola for her support and dedication shown during the experimental activities and also for her enthusiasm that enlightened the days spent in the lab. The authors want also to thank the laboratory LABCAMP ${ }^{2}$ (CESMA - University of Naples Federico II) for hosting some of the research activities.

Code availability Not applicable.

Author contribution Not applicable.

Funding Open access funding provided by Università degli Studi di Napoli Federico II within the CRUI-CARE Agreement.

Data availability The authors declare that, if required, they will share all the data.

\section{Declarations}

Conflict of interest The authors declare no competing interests.

Open Access This article is licensed under a Creative Commons Attribution 4.0 International License, which permits use, sharing, adaptation, distribution and reproduction in any medium or format, as long as you give appropriate credit to the original author(s) and the source, provide a link to the Creative Commons licence, and indicate if changes were made. The images or other third party material in this article are included in the article's Creative Commons licence, unless indicated otherwise in a credit line to the material. If material is not included in the article's Creative Commons licence and your intended use is not permitted by statutory regulation or exceeds the permitted use, you will need to obtain permission directly from the copyright holder. To view a copy of this licence, visit http://creativecommons.org/licenses/by/4.0/.

\section{References}

1. Dubourg L, Merati A, Jahazi M (2010) Process optimisation and mechanical properties of friction stir lap welds of 7075-T6 stringers on 2024-T3 skin. Mater Des 31:3324-3330. https://doi.org/10. 1016/j.matdes.2010.02.002

2. Williams JC, Starke EA (2003) Progress in structural materials for aerospace systems. 51:5775-5799. https://doi.org/10.1016/j. actamat.2003.08.023

3. Yin H, Li H, Su X, Huang D (2013) Materials Science \& Engineering A Processing maps and microstructural evolution of isothermal compressed $\mathrm{Al}-\mathrm{Cu}-\mathrm{Li}$ alloy. Mater Sci Eng A 586: 115-122. https://doi.org/10.1016/j.msea.2013.07.084

4. Zhang S, Zeng W, Yang W, Shi CL, Wang HJ (2014) Ageing response of a $\mathrm{Al}-\mathrm{Cu}-\mathrm{Li} 2198$ alloy. Mater Des 63:368-374. https://doi.org/10.1016/j.matdes.2014.04.063

5. Milagre MX, Donatus U, Machado CSC, Araujo JVS, da Silva RMP, de Viveiros BVG, Astarita A, Costa I (2019) Comparison of the corrosion resistance of an $\mathrm{Al}-\mathrm{Cu}$ alloy and an $\mathrm{Al}-\mathrm{Cu}-\mathrm{Li}$ alloy. Corros Eng Sci Technol 54:402-412. https://doi.org/10. 1080/1478422X.2019.1605472

6. Xu YB, Zhong WL, Chen YJ, et al (2001) Shear localization and recrystallization in dynamic deformation of $8090 \mathrm{Al}-\mathrm{Li}$ alloy. 299: 287-295

7. Krug ME, Seidman DN, Dunand DC (2012) Creep properties and precipitate evolution in $\mathrm{Al}-\mathrm{Li}$ alloys microalloyed with $\mathrm{Sc}$ and $\mathrm{Yb}$. Mater Sci Eng A 550:300-311. https://doi.org/10.1016/j.msea. 2012.04.075

8. Simar A, Avettand-Fènoël MN (2017) State of the art about dissimilar metal friction stir welding. Sci Technol Weld Join 22:389-403. https://doi.org/10.1080/13621718.2016.1251712

9. Astarita A, Prisco U, Squillace A, Velotti C, Tronci A (2015) Mechanical characterization by DOE analysis of AA6156-T4 friction stir welded joints in as-welded and post-weld aged condition. Mater Test 57:192-199. https://doi.org/10.3139/120.110698

10. Astarita A, Squillace A, Armentani E, Ciliberto S (2012) Friction stir welding of AA 2198 T3 rolled sheets in butt configuration. Metall Ital 104

11. Paulo RMF, Rubino F, Valente RAF, Teixeira-Dias F, Carlone P (2020) Modelling of friction stir welding and its influence on the structural behaviour of aluminium stiffened panels. Thin-Walled Struct 157:107128. https://doi.org/10.1016/j.tws.2020.107128

12. Sudhagar S, Sakthivel M, Ganeshkumar P (2019) Monitoring of friction stir welding based on vision system coupled with machine learning algorithm. Meas J Int Meas Confed 144:135-143. https:// doi.org/10.1016/j.measurement.2019.05.018

13. Alam MP, Sinha AN (2019) Fabrication of third generation Al-Li alloy by friction stir welding: a review. Sadhana - Acad Proc Eng Sci 44:1-13. https://doi.org/10.1007/s12046-019-1139-4

14. Paradiso V, Rubino F, Carlone P, Palazzo GS (2017) Magnesium and aluminium alloys dissimilar joining by friction stir welding. Procedia Eng 183:239-244. https://doi.org/10.1016/j.proeng.2017. 04.028

15. Ma YE, Xia ZC, Jiang RR, Li W (2013) Effect of welding parameters on mechanical and fatigue properties of friction stir welded 2198 T8 aluminum - lithium alloy joints. 114:1-11. https://doi.org/ 10.1016/j.engfracmech.2013.10.010

16. Buffa G, Campanile G, Fratini L, Prisco A (2009) Friction stir welding of lap joints : influence of process parameters on the metallurgical and mechanical properties. 519:19-26. https://doi.org/10. 1016/j.msea.2009.04.046

17. Gao C, Zhu Z, Han J, Li H (2015) Materials Science \& Engineering A Correlation of microstructure and mechanical properties in friction stir welded 2198-T8 Al - Li alloy. Mater Sci Eng A 639:489499. https://doi.org/10.1016/j.msea.2015.05.038

18. Tao Y, Ni DR, Xiao BL, Ma ZY, Wu W, Zhang RX, Zeng YS (2017) A Origin of unusual fracture in stirred zone for friction stir welded 2198-T8 Al-Li alloy joints. Materials Science \& Engineering 693:1-13. https://doi.org/10.1016/j.msea.2017.03.079

19. Cavaliere P, Cabibbo M, Panella F, Squillace A (2009) 2198 Al Li plates joined by Friction Stir Welding : mechanical and microstructural behavior. Mater Des 30:3622-3631. https://doi.org/10. 1016/j.matdes.2009.02.021

20. Cavaliere P, De Santis A, Panella F, Squillace A (2009) Effect of anisotropy on fatigue properties of $2198 \mathrm{Al}-\mathrm{Li}$ plates joined by friction stir welding. Eng Fail Anal 16:1856-1865. https://doi.org/ 10.1016/j.engfailanal.2008.09.024

21. Gibson BT, Ballun MC, Cook GE, Strauss AM (2015) Friction stir lap joining of 2198 aluminum - lithium alloy with weaving and pulsing variants. J Manuf Process 18:12-22. https://doi.org/10. 1016/j.jmapro.2014.12.002

22. Reimann M, Goebel J, Gartner TM, dos Santos JF (2017) Refilling termination hole in AA 2198-T851 by refill friction stir spot welding. J Mater Process Technol 245:157-166. https://doi.org/ 10.1016/j.jmatprotec.2017.02.025 
23. Baraka A, Panoutsos G, Cater S (2015) A real-time quality monitoring framework for steel friction stir welding using computational intelligence. J Manuf Process 20:137-148. https://doi.org/10.1016/ j.jmapro.2015.09.001

24. Mishra D, Roy RB, Dutta S, Pal SK, Chakravarty D (2018) A review on sensor based monitoring and control of friction stir welding process and a roadmap to Industry 4.0. J Manuf Process 36:373-397. https://doi.org/10.1016/j.jmapro.2018.10.016

25. Song Y, Yang X, Cui L, Hou X, Shen Z, Xu Y (2014) Defect features and mechanical properties of friction stir lap welded dissimilar AA2024 - AA7075 aluminum alloy sheets. J Mater 55:918. https://doi.org/10.1016/j.matdes.2013.09.062

26. Venkateswaran P, Reynolds AP (2012) Factors affecting the properties of Friction Stir Welds between aluminum and magnesium alloys. Mater Sci Eng A 545:26-37. https://doi.org/10.1016/j. msea.2012.02.069

27. Jandaghi MR, Badini C, Pavese M (2020) Dissimilar friction stir welding of AA2198 and AA7475 : effect of solution treatment and aging on the microstructure and mechanical strength. J Manuf Process 57:712-724. https://doi.org/10.1016/j.jmapro.2020.07.037

28. Astarita A, Squillace A, Scala A, Prisco A (2012) On the critical technological issues of friction stir welding T-joints of dissimilar aluminum alloys. J Mater Eng Perform 21:1763-1771. https://doi. org/10.1007/s11665-011-0073-3

29. Velotti C, Astarita A, Squillace A, Ciliberto S, Villano MG, Giuliani M, Prisco U, Montuori M, Giorleo G, Bellucci F (2013) On the critical technological issues of friction stir welding lap joints of dissimilar aluminum alloys. Surf Interface Anal 45:1643-1648. https://doi.org/10.1002/sia.5277

30. Braga DFO, De Sousa LMC, Infante V et al (2015) Aluminum friction stir weldbonding. Procedia Eng 114:223-231. https://doi. org/10.1016/j.proeng.2015.08.062

31. Perrella M, Berardi VP, Armentani E (2020) Mode I fracture toughness evaluation of adhesively bonded joints via J-Integral and DIC. 389:1900116. https://doi.org/10.1002/masy.201900116

32. Boccarusso L, Astarita A, Carlone P, Scherillo F, Rubino F, Squillace A (2019) Dissimilar friction stir lap welding of AA 6082 - Mg AZ31: force analysis and microstructure evolution. J Manuf Process 44:376-388. https://doi.org/10.1016/j.jmapro.2019. 06.022

33. Zimmer S, Langlois L, Laye J (2010) Experimental investigation of the influence of the FSW plunge processing parameters on the maximum generated force and torque. 201-215. https://oi.org/ 10.1007/s00170-009-2188-3

34. Astarita A, Squillace A, Carrino L (2014) Experimental study of the forces acting on the tool in the friction-stir welding of AA $2024 \mathrm{~T} 3$ Sheets. J Mater Eng Perform 23:3754-3761. https://doi.org/10. 1007/s11665-014-1140-3

35. Mishra RS, Ma ZY (2005) Friction stir welding and processing. 50: 1-78. https://doi.org/10.1016/j.mser.2005.07.001

36. Mehta KP, Carlone P, Astarita A, Scherillo F, Rubino F, Vora P (2019) Conventional and cooling assisted friction stir welding of AA6061 and AZ31B alloys. Mater Sci Eng A 759:252-261. https:// doi.org/10.1016/j.msea.2019.04.120

37. Carlone P, Astarita A, Rubino F, Pasquino N (2016) Microstructural aspects in FSW and TIG welding of cast ZE41A magnesium alloy. Metall Mater Trans B Process Metall Mater Process Sci 47:1340-1346. https://doi.org/10.1007/s11663-0150536-2

38. Naik BS, Chen DL, Cao X, Wanjara P (1991) Microstructure and fatigue properties of a friction stir lap welded magnesium alloy. https://doi.org/10.1007/s11661-013-1728-5

39. Chowdhury SH, Chen DL, Bhole SD, Cao X, Wanjara P (2013) Materials Science \& Engineering A Lap shear strength and fatigue behavior of friction stir spot welded dissimilar magnesium-toaluminum joints with adhesive. Mater Sci Eng A 562:53-60. https://doi.org/10.1016/j.msea.2012.11.039

40. Babu S, Janaki Ram GD, Venkitakrishnan PV et al (2012) Microstructure and mechanical properties of friction stir lap welded aluminum alloy AA2014. J Mater Sci Technol 28:414-426. https:// doi.org/10.1016/S1005-0302(12)60077-2

41. Astarita A, Bitondo C, Squillace A, Armentani E, Bellucci F (2013) Stress corrosion cracking behaviour of conventional and innovative aluminium alloys for aeronautic applications. Surf Interface Anal 45:1610-1618. https://doi.org/10.1002/sia.5234

42. Cahn H (1996) PHYSICAL METALLURGY. Elsevier B Ser I: 1996. https://doi.org/10.1016/B978-0-444-89875-3.50040-5

43. Carlone P, Palazzo GS (2013) Influence of process parameters on microstructure and mechanical properties in AA2024-T3 friction stir welding. Metallogr Microstruct Anal 2:213-222. https://doi. org/10.1007/s13632-013-0078-4

44. Zhou HT, Li QB, Zhao ZK, Liu ZC, Wen SF, Wang QD (2010) Hot workability characteristics of magnesium alloy AZ80 - a study using processing map. Mater Sci Eng A 527:2022-2026. https:// doi.org/10.1016/j.msea.2009.12.009

45. Kim SI, Yoo YC (2001) Dynamic recrystallization behavior of AISI 304 stainless steel. Mater Sci Eng A 311:108-113. https:// doi.org/10.1016/S0921-5093(01)00917-0

46. Dehghan-Manshadi A, Barnett MR, Hodgson PD (2008) Recrystallization in AISI 304 austenitic stainless steel during and after hot deformation. Mater Sci Eng A 485:664-672. https://doi. org/10.1016/j.msea.2007.08.026

47. Ueki M, Horie S, Nakamura T (1985) Critical condition for transition from multiple to single peak dynamic recrystallization. Scr Metall 19:547-549. https://doi.org/10.1016/0036-9748(85)901322

48. Zhang X, Ma F, Zhang W, Li X (2014) Kinetics of dynamic recrystallization in AA2024 aluminum alloy. Mod Appl Sci 8:47-52. https://doi.org/10.5539/mas.v8n6p47

49. Quan GZ, Mao YP, Li GS, Lv WQ, Wang Y, Zhou J (2012) A characterization for the dynamic recrystallization kinetics of asextruded 7075 aluminum alloy based on true stress-strain curves. Comput Mater Sci 55:65-72. https://doi.org/10.1016/j.commatsci. 2011.11.031

50. Cederqvist L, Reynolds AP (2001) Factors affecting the properties of friction stir welded aluminum lap joints. Weld J (Miami, Fla) 80: 281/s-287/s

51. Fersini D, Pirondi A (2008) Analysis and modelling of fatigue failure of friction stir welded aluminum alloy single-lap joints. Eng Fract Mech 75:790-803. https://doi.org/10.1016/j. engfracmech.2007.04.013

52. Cao X, Jahazi M (2011) Effect of tool rotational speed and probe length on lap joint quality of a friction stir welded magnesium alloy. Mater Des 32:1-11. https://doi.org/10.1016/j.matdes.2010.06.048

53. Shirazi H, Kheirandish S, Pouraliakbar H (2020) Employing hooking and effective sheet thickness to achieve optimum failure load in lap joints of friction stir welded AA5456 aluminum. Theor Appl Fract Mech 105:102423. https://doi.org/10.1016/j.tafmec. 2019.102423

54. Cavaliere P, Squillace A, Panella F (2008) Effect of welding parameters on mechanical and microstructural properties of AA6082 joints produced by friction stir welding. J Mater Process Technol 200:364-372. https://doi.org/10.1016/j.jmatprotec.2007.09.050

Publisher's note Springer Nature remains neutral with regard to jurisdictional claims in published maps and institutional affiliations. 